\title{
The future of telesurgery: a universal system with haptic sensation
}

\section{Uzaktan cerrahinin geleceği: Dokunma duygusu hissi veren evrensel bir sistem}

\author{
Michael Stark ${ }^{1}$, Tahar Benhidjeb ${ }^{1,2}$, Stefano Gidaro ${ }^{3}$, Emilio Ruiz Morales ${ }^{4}$ \\ 'The New European Surgical Academy (NESA), Berlin, Germany \\ 2Department of General, Visceral and Thoracic Surgery, University Medical Center Hamburg-Eppendorf, Hamburg, Germany \\ ${ }^{3}$ Department of Surgical Science University “G. D'Annunzio” Chieti-Pescara, Italy \\ ${ }^{4}$ ALF-X Surgical Robotics Department, SOFAR S.p.A., Milan, Italy
}

Dear editor;

The $19^{\text {th }}$ century will be remembered as the era of abdominal surgery, and the $20^{\text {th }}$ as that of endoscopy. The $21^{\text {st }}$ century has a potential to become the era of telesurgery, should the technical developments bring added value to the existing surgical methods. The optimal telesurgical system should be suitable to any kind of surgical procedure and provide tactile sensing, $3 D$ vision as well as cost-effectiveness.

The Joint Research Centre (JRC) of the European Commission, in collaboration with SOFAR S.p.A. in Milan, Italy, initiated a project to meet these demands, the Telelap Alf-x. The New European Surgical Academy is providing the academic background to such a demanding project. This system enables universal telesurgical procedures with optimal ergonomy and haptic sensation. The preclinical studies have proven an optimal outcome and it seems that the system will replace several endoscopic procedures in the $21^{\text {st }}$ century.

During the $19^{\text {th }}$ century, along with the development of general anaesthesia (1), surgical procedures became routine, and certain novel operative methods were developed, some of which are in use even today, such as the Billroth or the Wertheim operations $(2,3)$.

Georg Kelling, a German surgeon, was the first to perform an experimental laparoscopy (4). Throughout the $20^{\text {th }}$ century, the introduction of endotracheal intubation (5), the insufflator (6), light sources (6) and other designed instruments enabled the development of many endoscopic procedures.

Today, most operations can be performed endoscopically (7), especially the gynaecological ones, namely, the laparoscopically assisted vaginal hysterectomy (8) and the total abdominal hysterectomy (9). The patients undergoing endoscopic procedures need less postoperative analgesics and present decreased morbidity with shorter hospital stay (10).
At the end of the $20^{\text {th }}$ century, it seemed that surgery had reached its peak.

The potential and vision of future remote operations in space and on other planets led to the development of telesurgical devices (11). Although we are still on Mother Earth, this idea stimulated the development of various systems. The era of telesurgery started in 1988 when the PUMA telesurgical system was used for a controlled neurosurgical biopsy (12). Other systems in use at present or in the past are the Da Vinci (13), Probot (14), Robodoc (15), and Zeus (16).

The term "robotic" prevails in the literature. However, it is misleading since none of the existing telesurgical systems is equipped with artificial intelligence. The term "telesurgery" should be preferred.

The accumulated advantages of the existing telesurgical systems are improved dexterity and accuracy, 3D stereo-vision, lack of tremor, and the potential of telementoring and operating from remote cities and countries. The most important disadvantage in all existing systems is the lack of haptic feedback.

Exactly like musicians who use their fingers for producing the desired sound and, in case of string instruments, feel the vibrations of the strings, it is of utmost importance for a surgeon to be able to feel the consistency and anatomical structures and evaluate the tensility of the suture during knot-tying.

Haptic sensation during surgery should be part of any telesurgical system, even if its relevance in telesurgical procedures is controversial, and it has been claimed that the results of visual force feedback and haptic feedback are comparable (17). In a recent study, differences between strand-to-strand knots and loop-to-strand knots were detected when telesurgical and manual knot-tying were compared (18).

In the past, surgeons used their fingertips to hold and manipulate instruments. In endoscopy, the trocar as well as other instruments are manipulated with the fists or the proximal parts of the fingers.

Address for Correspondence: Tahar Benhidjeb, University Medical Center Hamburg-Eppendorf, Department of General, Visceral and Thoracic Surgery, Martinistr. 52 20246 Hamburg, Germany Phone: +49 40741051490 e.mail: t.benhidjeb@uke.de (C) Copyright 2012 by the Turkish-German Gynecological Education and Research Foundation - Available online at www.jtgga.org doi:10.5152/jtgga.2012.05 
Telesurgical systems should provide safety, accuracy, optimal short and long time outcomes and optimal ergonomy. Costeffectiveness should always be considered.

Any surgical development should only be applied if it provides added value to the existing systems.

To meet these demands, the EU commission, in collaboration with SOFAR S.p.A. in Milan, Italy, has initiated a different telesurgical system, the Telelap Alf-x, which has been designed in order to meet the needs of patients and surgeons with the aim to provide added value to existing procedures (Figure 1).

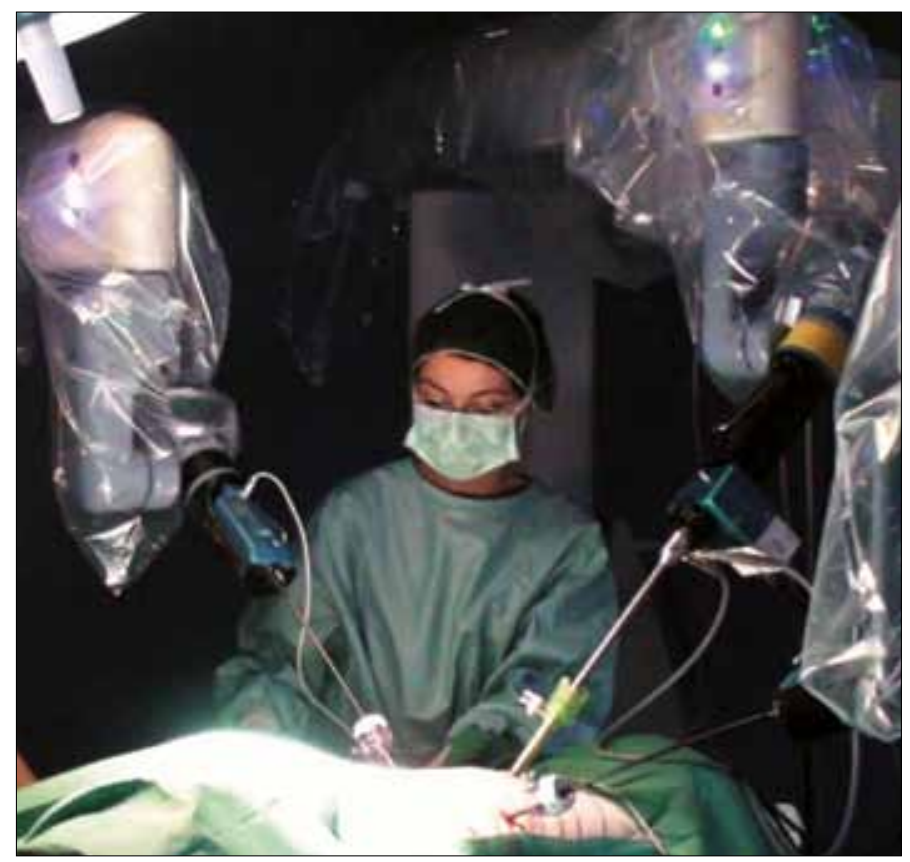

Figure 1. The Telelap-Alf-x system in work

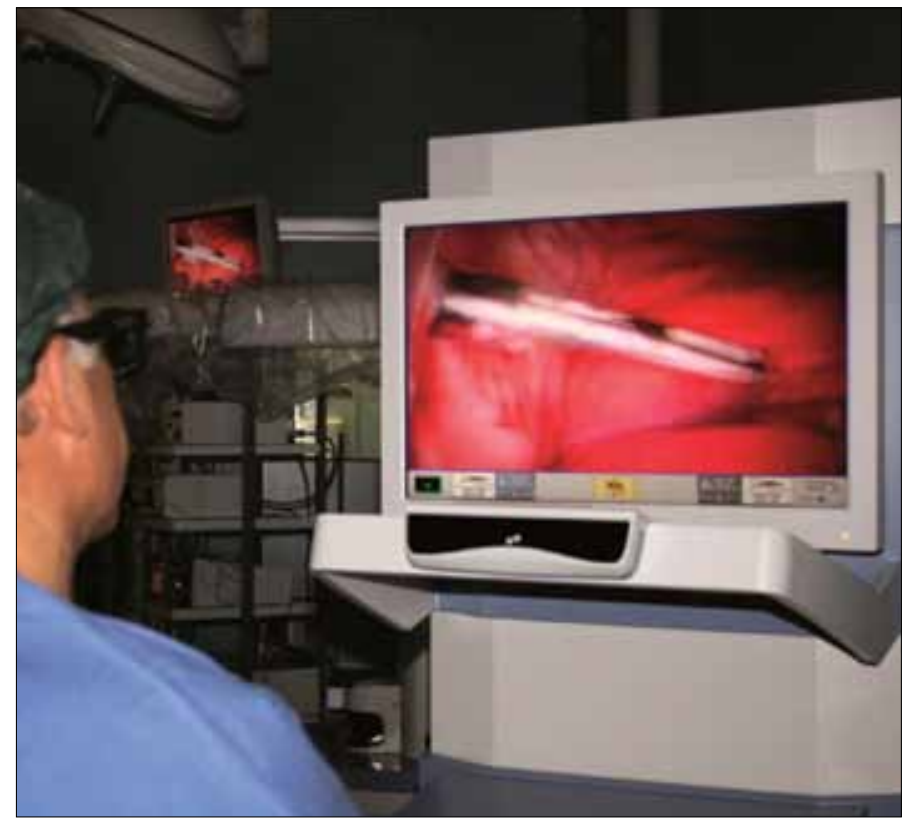

Figure 2. Eye-tracking system
The features of the system are as follows:

1. 3 or 4 arms combined with 1 or 2 consoles, according to the needs. As the arms are separately moveable, immediate access to the patient is possible in case of an emergency;

2. Fast docking: all instruments are connected to the arms with magnets - immediate exchange of needed instruments;

3. The system detects within seconds the optimal pivot point of each inserted instrument. This point becomes the axis of the arm movement, preventing extension of the entry point;

4. Avoidance of tremor, advanced control and limitation of applied forces;

5. Haptic sensation and newly designed handles enabling manipulation of the instruments with the fingers;

6. Placing the instruments at any given angle needed. The system can access the abdominal cavity from the abdomen and, in women, through the pouch of Douglas, therefore transdouglas surgery is possible with this system;

7. A console with unobstructed view onto the screen with $3 \mathrm{D}$ vision and an ergonomic seat enabling a comfortable position during long operations;

8. Cost-effectiveness: the surgeon can use low-cost disposable instruments, however, the system provides reusable instruments;

9. Universality: any existing endoscopic instrument (articulated tip, monopolar, bipolar, laser etc. instruments) can be adapted. Therefore, surgeons do not have to change their operative habits and can even use the system for training;

10. An unique eye-tracking system. Next to the 3D vision, the surgeon controls the insertion of instruments by looking at the corresponding icon on the screen, the picture is magnified when his/her head approaches the screen, and any point looked at moves to the centre of the screen (Figure 2).

In the first experimental operations performed using the Telelap Alf-x, the average time for cholecystectomy was 31.75 min as compared to 91 min using a conventional telesurgical system (1). We strongly believe that haptic sensation provided more confidence to the surgeon, which explains the shorter operation time.

No surgical system can provide an optimal outcome when the surgical steps are not taken according to an evidence-based programme (20). At the same time, only standardized and optimized surgical methods will allow valuable meta-analysis and enable a comparison of surgical outcome in different institutions and by different surgeons (21). Therefore, a group of internationally renowned opinion leaders was assigned to design evidence-based surgical procedures in various disciplines.

The Telelap-Alf-x provides a combination of unobstructed 3D vision, haptic feedback and universality which offers all the advantages of laparotomy along with those of endoscopy. Therefore, this system will be the basis of novel surgical developments during the $21^{\text {st }}$ century. 


\section{References}

1. Cottineau C, Cocaud J, Jacob JP. Les débuts de l'anesthésie. Allerg Immunol (Paris) 1998; 30: 135-7.

2. Busman DC. Theodor Billroth 1829 - 1894. Acta Chir Belg 2006; 106: 743-52.

3. Köhler G. 100 years of the Wertheim operation--Ernst Wertheim between myth and reality. Zentralbl Gynakol 1999; 121: 121-5.

4. Schollmeyer T, Soyinka AS, Schollmeyer M, Meinhold-Heerlein I. Georg Kelling (1866-1945): the root of modern day minimal invasive surgery. A forgotten legend? Arch Gynecol Obstet 2007; 276: 505-9. [CrossRef]

5. Baggot MG. The endotracheal tube in situ as a foreign body: the master key to general anesthesia, its mechanism and inherent (though not peculiar) complications and to effective 'life support'. Med Hypotheses 2002; 59: 742-50. [CrossRef]

6. Dukanović $\mathrm{S}$, Canić $\mathrm{T}$. The value of hysteroscopy in perimenopausal women. Acta Med Croatica 2007; 61: 185-90.

7. Nezhat C. Operative endoscopy will replace almost all open procedures. JSLS 2004; 8: 101-2.

8. Mettler L, Ahmed-Ebbiary N, Schollmeyer T. Laparoscopic hysterectomy: Challenges and limitations. Minim Invasive Ther Allied Technol 2005; 14: 145-59. [CrossRef]

9. Parkar RB, Kamau WJ, Otieno D, Baraza R. Total laparoscopic hysterectomy at the Aga Khan University Hospital, Nairobi. East Afr Med J 2007; 84: 508-15.

10. Ng SS, Li JC, Lee JF, Yiu RY, Leung KL. Laparoscopic total colectomy for colorectal cancers: a comparative study. Surg Endosc 2006; 20: 1193-6. [CrossRef]

11. Haidegger T, Sándor J, Benyó Z. Surgery in space: the future of robotic telesurgery. Surg Endosc 2011; 25: 681-90. [CrossRef]
12. Kwoh YS, Hou J, Jonckheere EA, Hayati S. A robot with improved absolute positioning accuracy for CT guided stereotactic brain surgery. IEEE Trans Biomed Eng 1988; 35: 153-60. [CrossRef]

13. Kang CM, Kim DH, Lee WJ, Chi HS. Conventional laparoscopic and robot-assisted spleen-preserving pancreatectomy: does da Vinci have clinical advantages? Surg Endosc 2011; 25: 2004-9. [CrossRef]

14. Harris SJ, Arambula-Cosio F, Mei Q, Hibberd RD, Davies BL, Wickham JE, Nathan MS, 15. Kundu B. The Probot--an active robot for prostate resection. Proc Inst Mech Eng H 1997; 211: 317-25. [CrossRef]

15. Hananouchi T, Nakamura N, Kakimoto A, Yohsikawa H, Sugano N. CT-based planning of a single-radius femoral component in total knee arthroplasty using the ROBODOC system. Comput Aided Surg 2008; 13: 23-9. [CrossRef]

16. Zhou HX, Guo YH, Yu XF, Bao SY, Liu JL, Zhang Y, et al. Zeus robotassisted laparoscopic cholecystectomy in comparison with conventional laparoscopic cholecystectomy. Hepatobiliary Pancreat Dis Int 2006; 5: 115-8.

17. Reiley CE, Akinbiyi T, Burschka D, Chang DC, Okamura AM, Yuh DD. Effects of visual force feedback on robot-assisted surgical task performance. J Thorac Cardiovasc Surg. 2008; 135: 196-202. [CrossRef]

18. Reynisson P, Shokri E, Bendahl PO, Persson J. Tensile strength of surgical knots performed with the da Vinci surgical robot. J Minim Invasive Gynecol 2010; 17: 365-70. [CrossRef]

19. Jayaraman S, Davies W, Schlachta CM. Getting started with robotics in general surgery with cholecystectomy: the Canadian experience. Can J Surg 2009; 52: 374-8. [CrossRef]

20. Stark M, Gerli S, Di Renzo GC. The importance of analyzing and standardizing surgical methods. J Minim Invasive Gynecol 2009; 16: 122-5.

21. Stark M. Optimised meta-analysis should be based on standardised methods. BJOG. 2011; 118: 765-6. [CrossRef] 